\title{
EFFECT OF PROCESS VARIABILITY ON THE ECONOMIC VALUES OF AVERAGES CONTROL CHART PARAMETERS
}

\author{
A. Wazeer \\ Department of Production Engineering, Industrial Education College , \\ Beni-Suef, Egypt
}

(Received March 27, 2006 Accepted May 4, 2006)

\begin{abstract}
When the averages control chart is applied to monitor a manufacturing process, three parameters should be determined, sample size, sampling interval between successive samples and the control limit for the chart. This study shows how the effect of process variability caused by common and assignable causes on the values of averages control chart parameters. An example is presented and then based on this example, sensitivity analysis is performed to show the direction of control chart parameters changes in the presence of changes in the magnitude and frequency of process shift and the costs of discovering and correcting the causes of these shifts.
\end{abstract}

KEYWORDS: Process variability, Control Chart for Averages.

\section{INTRODUCTION}

The control charts used to continuously monitor the production process to quickly detect any deterioration in quality. Part of the observed variation in a quality variable is caused by complex set of causes, and the variations produced by these causes can be treated an inherent to the process in its current state. The causes, which produce this random or chance variation, are called common causes because their effect is common to all of the process output. The variation produced by any one individual common cause is small, but the total variation produced by all of the common causes together can be substantial. In addition to the common causes that produced the random variation, there may be other sources of variation, called assignable causes or special causes, which are present at certain times and which can individually produce a substantial amount of variation. The main purpose of a control chart is to detect special causes of variation so that these causes can be found and eliminated.

One of the simplest control charts is the averages control chart $(\overline{\boldsymbol{X}}$ - chart) originally developed by Shewhart (1931). This control chart is designed for detecting special causes, which produce a change in the mean of the process. When an $\bar{X}$ - chart is used to monitor a process, three parameters should be determined: the sample size (n), the sampling interval between successive sample (h) and the control limits of the chart (k). Duncan [1] presented the first cost model to determine the three parameters for the $\overline{\boldsymbol{X}}$-chart, which is called the economic design of $\overline{\boldsymbol{X}}$ - chart. The problem with 
the commonly used rational approach to control chart design is that it is used in almost all process as the standard procedure for implementing control charts without regard to the cost consequences of the design. In order to overcome this shortcoming, a number of researchers have proposed economic models for the design of control charts, e.g. [2-9]. These models have not been widely used because the models are complex, and difficult to use. Also, these models are typically optimized for a particular size of process mean shift, frequency of out of control, and cost of diagnosis. In practice, the mean period of the process remains in control is not static, the size of the process shift is not constant and the cost of diagnosis change with time. Williams [10] incorporated the concept of statistical consideration into the economic design of control charts and presented the economic statistical design of $\bar{X}$ - chart for normal data. Review of the literature in economic designs of control charts has been published by Ho and Case [11]. Alexander [12] presented economic model of $\overline{\boldsymbol{X}}$ - chart with Taguch's loss function to incorporate losses that result from process mean departure from target value. Chau and Cheng [13] presented minimum loss design of $\overline{\boldsymbol{X}}$ - charts for nonnormal data. Chou et al [14] developed the economic design of $\overline{\boldsymbol{X}}$ - charts for correlated data. Bai and Lee [15] presented variable sampling interval $\overline{\boldsymbol{X}}$ - control charts with an improved switching rule which use a long sampling interval if consecutive sample means fall close to control chart centerline and short interval otherwise. Chen and LIAO [16] presented a model for the design of an $\overline{\boldsymbol{X}}$ control chart from a multiple criteria. With this model, sets of design parameters $(n, h, k)$ for the $\overline{\boldsymbol{X}}$ chart are chosen based on data envelopment analysis and provide the quality control manager a variety of choices to arrive at the requirement of long run quality of product or minimal cost concurrently.

The effect of process variability caused by common and assignable causes on the $\bar{X}$ - chart parameters are not considered in the most of the previous studies. In this study, Duncan's cost model for $\overline{\boldsymbol{X}}$ - chart is employed as the objective function, which is intended to be minimized. This function is used with the Taguchi loss function to consider losses due to in -control and out -of -control variability. The direction of control chart parameters changes due to changes in magnitude and frequency of process shift and the costs of discovering and correcting the causes of these shifts are presented. In the next section, Duncan's cost model will review and the effect of process variability caused by common and assignable causes on the values of averages control chart parameters will be presented.

\section{THEORETICAL ANALYSIS}

In this section, the cost model for $\bar{X}$ - chart given by Duncan will be reviewed. Also, the Duncan's cost model with Taguchi's loss function will be presented. Duncan's cost model for $\overline{\boldsymbol{X}}$ - chart is more realistic than the other models. The components of Duncan's cost model include:

(1) the cost of an out-of-control condition;

(2) the cost of false alarms; 
(3) the cost of searching for an assignable cause; and

(4) the cost of sampling, inspection, evaluation and plotting.

Duncan assumes that the process starts in control and subject to random shifts in the process mean. Once a shift occurs, the process remains there until corrected. The cycle length is defined as the total time from which the process starts in-control, shifts to an out-of-control condition, has the out-of-control condition detected, and results in the assignable cause being identified. These four time intervals are respectively the interval the process is in-control, the interval the process is out-of-control before the final sample of the detecting subgroup is taken, the interval to sample, inspect, evaluate and plot the subgroup results, and the interval to search for assignable cause. When the average cycle length is determined, the cost components can be converted to a per hour of operation basis. Given associated cost and time parameters, the optimal values of the three decision parameters for the model are then determined by using optimization techniques. In Duncan's model, the four average cycle length components are as follows.

(1) Assuming that the process begins in the in-control state, the time interval that the process remains in control is an exponential random variable with a mean $1 / \lambda$, which is the average process in-control time.

(2) When an assignable cause occurs, the probability that this out-of-control condition will be detected on any subsequent subgroup is $1-\beta$, which is the power of the chart. Thus, the expected number of subgroups taken before a shift in the process mean is detected is $1 /(1-\beta)$. The average time of occurrence within an interval between the $j$ th and $(j+\boldsymbol{l}) \boldsymbol{s t}$ subgroups, given an occurrence of the shift in the interval between these subgroups, is

$$
\tau=\frac{1-(1+\lambda \boldsymbol{h}) e^{-\lambda \boldsymbol{h}}}{\lambda\left(1-e^{-\lambda \boldsymbol{h}}\right)}
$$

Therefore, the expected length of the out-of-control period is $\frac{\boldsymbol{h}}{(\boldsymbol{l}-\boldsymbol{\beta})}-\tau$.

(3) The average sampling, inspecting, evaluating and plotting time for each sample is a constant $\boldsymbol{g}$ proportional to the sample size $\boldsymbol{n}$, so that the delay in plotting a subgroup point on the $\bar{X}$ - chart is $\boldsymbol{g} \boldsymbol{n}$.

(4) The time to search for the assignable cause following an action signal is a constant $D$.

Therefore, the expected length of a cycle, denoted by $\boldsymbol{E}(\boldsymbol{T})$, is

$$
E(T)=\frac{1}{\lambda}+\frac{h}{1-\beta}-\tau+g n+D
$$

and the expected cost per hour, denoted by $\boldsymbol{E}(\boldsymbol{C})$, incurred by the process is 


$$
E(C)=\frac{a_{1}+a_{2} n}{h}+\frac{a_{4}\left[E(T)-\left(\frac{1}{\lambda}\right)\right]+a_{3}+\alpha a_{5} e^{\frac{-\lambda h}{1-e^{-\lambda h}}}}{E(T)}
$$

Where $\boldsymbol{a}_{1}$ and $\boldsymbol{a}_{2}$ the respectively the fixed and variable components of sampling cost, $\boldsymbol{a}_{3}$ is the cost of searching for an assignable cause, $\boldsymbol{a}_{\mathbf{4}}$ represents the hourly penalty cost associated with production in the out-of-control state, and $\boldsymbol{a}_{\mathbf{5}}$ is the cost of investigating a false alarm. The economic design of an $\bar{X}$ - chart is to determine the appropriate values of $\boldsymbol{n}, \boldsymbol{h}$ and $\boldsymbol{k}$ such that $\boldsymbol{E}(\boldsymbol{C})$ may be minimized.

The Taguchi loss function provides a means of explicitly considering the loss due to process variability. Taguchi introduced the quality loss function as a quality performance measure for a product. Consider a product with bilateral tolerances of equal $\Delta$. If the loss ( or cost) to society of producing a product out of specification is $\boldsymbol{A} \$$ / unit , then the Taguchi loss function defines the expected loss to society as

Expected loss per unit $=\frac{A}{\Delta^{2}} V^{2}$

Where $V^{2}$ is the mean squared deviation of the process, defined as

$$
V^{2}=\sigma^{2}+(T-\mu)^{2}
$$

and $\boldsymbol{T}$ is the target of the process characteristic. When the process is in control, its mean is centered on the target (i.e., $\mu=T$ ), and its $V^{2}=V_{1}^{2}=\sigma^{2}$. When the process mean shifts to $\boldsymbol{\mu}=\boldsymbol{T}+\delta \sigma$, its mean shifts of process target and

$$
V^{2}=V_{2}^{2}=\sigma^{2}+(\mu-T)^{2}
$$

By assuming that the production rate is $\boldsymbol{P}$ units / hr and applying some approximations on the terms of equation (3) such as

$$
\tau \approx \frac{h}{2}-\frac{\lambda h^{2}}{12}, B=\left[\frac{1}{1-\beta}-\frac{1}{2}+\frac{\lambda h}{12}\right] h+D+g n, \frac{\alpha \exp (-\lambda h)}{1-\exp (-\lambda h)} \approx \frac{\alpha}{\lambda h},
$$

$\boldsymbol{L}_{1}=\frac{A}{\Delta^{2}} \boldsymbol{V}_{1}^{2}$ and $\boldsymbol{L}_{2}=\frac{A}{\Delta^{2}} \boldsymbol{V}_{2}^{2}$, the expected cost (or loss) per hour, denoted by $\boldsymbol{E}(\boldsymbol{L})$, can be obtained as

$$
E(L)=\frac{a_{1}+a_{2} n}{h}+\frac{a_{3} \lambda+a_{5} \alpha / h+L_{1} P+L_{2} P \lambda B}{1+\lambda B}
$$

Equation (7) determines the minimum loss design of an $\bar{X}$ - chart involves determining the optimal values of the sample size (n), the sampling interval between 
successive sample (h) and the control limits of the chart (k) such that $\boldsymbol{E}(\boldsymbol{L})$ is minimized. In other words, the optimal values for $\mathrm{n}, \mathrm{h}$ and $\mathrm{k}$ can be obtained by minimizing the above cost function, $\boldsymbol{E}(\boldsymbol{L})$.

\section{AN EXAMPLE AND ITS SOLUTION}

In this section, an example is presented to illustrate the solution procedure of the minimum loss design of an $\overline{\boldsymbol{X}}$ - chart. A plant manufactures packed orange juice that has a quantity of content specification of $250 \mathrm{cc}$ with a tolerance of $\pm 0.3 \mathrm{cc}$ (i.e., $\boldsymbol{\Delta}=\boldsymbol{0 . 3}$ ). From past data, the process standard deviation is estimated as $0.1 \mathrm{cc}$ (i.e., $\sigma=0.1$ ). Process shifts occur at random with a frequency of about one every 4 hours of operation $(\lambda=0.25)$. The manufacturer uses $\bar{X}$-chart to monitor the process. Based on an analysis of quality control technicians salaries and the costs of test equipment, it is estimated that the fixed cost of taking a sample is $\$ 1$ (i.e., $\boldsymbol{a}_{\boldsymbol{1}}=\mathbf{1}$ ). The estimated variable cost of sampling is about $\$ 0.10$ per quantity of content (i.e., $\boldsymbol{a}_{2}=\mathbf{0 . 1 0}$ ) and it takes approximately 0.01 hour (i.e., $\boldsymbol{g}=\mathbf{0 . 0 1}$ ) to measure and record the quantity of content of a bottle of orange juice. On average, when the process goes out of control, the magnitude of the shift is approximately one standard deviation ( $\boldsymbol{\delta}=\mathbf{1 . 0}$ ). The average time required to investigate an out of control signal is two hours (i.e., $\boldsymbol{D}=\mathbf{2}$ ). The cost of investigating an action signal that results in the elimination of an assignable cause is $\$ 50$ while the cost of investigating a false alarm is $\$ 50$ (i.e., $\boldsymbol{a}_{\mathbf{3}}=\mathbf{5 0}$ and $\boldsymbol{a}_{\mathbf{5}}=\mathbf{5 0}$ ). The process is assumed to continue to produce packed orange juices at a rate of $100 / \mathrm{h}$ during the period of investigating and elimination of out-of-control signals (i.e., $\boldsymbol{P}=\mathbf{1 0 0}$ ). The cost of reworking or scraping a package of juice that is found to be outside the specification limits is $\$ 5$ (i.e., $\boldsymbol{A}=5$ ).

A computer program is coded for minimization of the cost model in equations (3) and (7). The program calculates the optimum values of $\mathrm{n}, \mathrm{h}$ and $\mathrm{k}$ by evaluating a wide range of possible solutions. For a certain combination of $\boldsymbol{n}, \boldsymbol{h}$ and $\boldsymbol{k}$, the program also calculates the corresponding $\alpha$ risk and power $1-\beta$. The computer program is found in the Appendix. This program is easy to run on any computer with BASIC. The output from this program, using the values of the model parameters given in the above example, is shown in Table 1. The program calculates the optimal control limit width $\boldsymbol{k}$ and sampling frequency $\boldsymbol{h}$ for values of $\boldsymbol{n}$ and resulting values of the cost function. The optimal control chart design can be found by inspecting the values of the cost function to find the minimum. From table 1, note that the minimum cost is 88.45 per hour, and the optimal $\overline{\boldsymbol{X}}$ - chart would use samples of size $\boldsymbol{n}=\boldsymbol{1 1}$, the control limits would be located at $\pm k \sigma / \sqrt{n}$, with $k=2.5$, and the samples would be taken at intervals of $\boldsymbol{h}=\mathbf{1 . 1}$ hour (about every $66 \mathrm{~min}$.). Type I error probability of this design is $\alpha=\mathbf{0 . 0 2}$, and the power of the chart is $\mathbf{1}-\boldsymbol{\beta}=\mathbf{0 . 7 8}$. 
Table 1: The results of a computer search for the optimum design parameters.

\begin{tabular}{|c|c|c|c|c|c|}
\hline $\begin{array}{c}\text { Sample } \\
\text { Size } \\
\boldsymbol{n}\end{array}$ & $\begin{array}{c}\text { Control } \\
\text { Limit } \\
\text { Width } \\
\boldsymbol{k}\end{array}$ & $\begin{array}{c}\text { Sampling } \\
\text { Interval } \\
\boldsymbol{h}\end{array}$ & $\begin{array}{c}\text { Type 1 } \\
\text { Error } \\
\boldsymbol{\alpha}\end{array}$ & $\begin{array}{c}\text { Power of } \\
\text { the Chart } \\
\boldsymbol{1}-\boldsymbol{\beta}\end{array}$ & $\begin{array}{c}\text { Cost per hour } \\
\boldsymbol{E}(\boldsymbol{L}),(\$)\end{array}$ \\
\hline 2 & 1.8 & 0.7 & 0.07 & 0.35 & 90.07 \\
\hline 3 & 1.9 & 0.7 & 0.06 & 0.43 & 91.64 \\
\hline 4 & 2.1 & 0.8 & 0.04 & 0.46 & 90.69 \\
\hline 5 & 2.1 & 0.8 & 0.04 & 0.55 & 90.02 \\
\hline 6 & 2.2 & 0.9 & 0.03 & 0.60 & 90.54 \\
\hline 7 & 2.2 & 0.9 & 0.03 & 0.67 & 89.20 \\
\hline 8 & 2.3 & 1.0 & 0.02 & 0.74 & 89.60 \\
\hline 10 & 2.4 & 1.0 & 0.02 & 0.76 & 88.65 \\
\hline 11 & 2.5 & 1.1 & 0.02 & 0.78 & 88.45 \\
\hline 12 & 2.5 & 1.1 & 0.01 & 0.82 & 88.52 \\
\hline 13 & 2.6 & 1.2 & 0.01 & 0.87 & 88.70 \\
\hline
\end{tabular}

\section{SENSITIVITY ANALYSIS}

Continuing the above example, the behavior of the presented model through sensitivity analysis are investigated, the sensitivity of the $\bar{X}_{- \text {control chart parameters }}$ such as, sample size (n) and sampling interval between successive samples (h) are shown in figures 1-4. Figures $\mathbf{1}$ and $\mathbf{2}$ show the changes in the optimum sample size and optimum sampling interval versus the mean time between assignable causes $(1 / \lambda)$. These figures indicate that, when the mean time between assignable causes increases, the optimum sample size increases and the optimum sampling interval decreases. Figures $\mathbf{3}$ and $\mathbf{4}$ indicate that, increases in the magnitude of the shift in process average warrants a decrease in the sample size and the sampling frequency.

\section{CONCLUSIONS}

From the previous discussion the following conclusions can be drawn:

1- The presented model for designing $\bar{X}$ - control chart parameters defines losses owing to the process variability caused by both chance and assignable causes.

2- To keep the cost low, the $\bar{X}$ - control chart parameters must be adjusted based on the mean time between assignable causes and the required magnitude of the shift in the process average to be detected.

3- Small mean time between assignable causes requires smaller value of sample size, while requires larger value of sampling interval.

4- Small process shift requires larger values of sample size and sampling interval to be detected. 


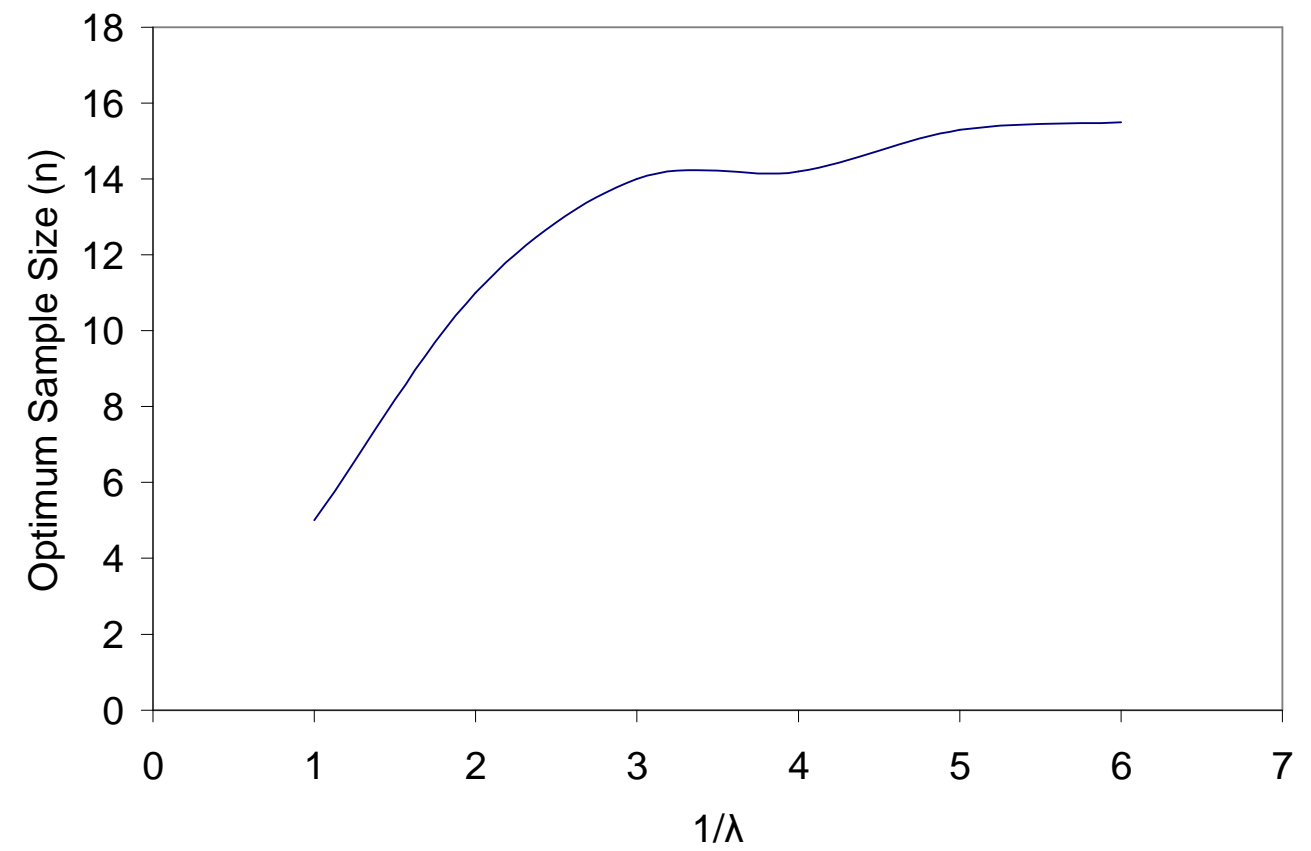

Fig. 1: Optimum sample size versus the mean time between assignable causes $(1 / \lambda)$.

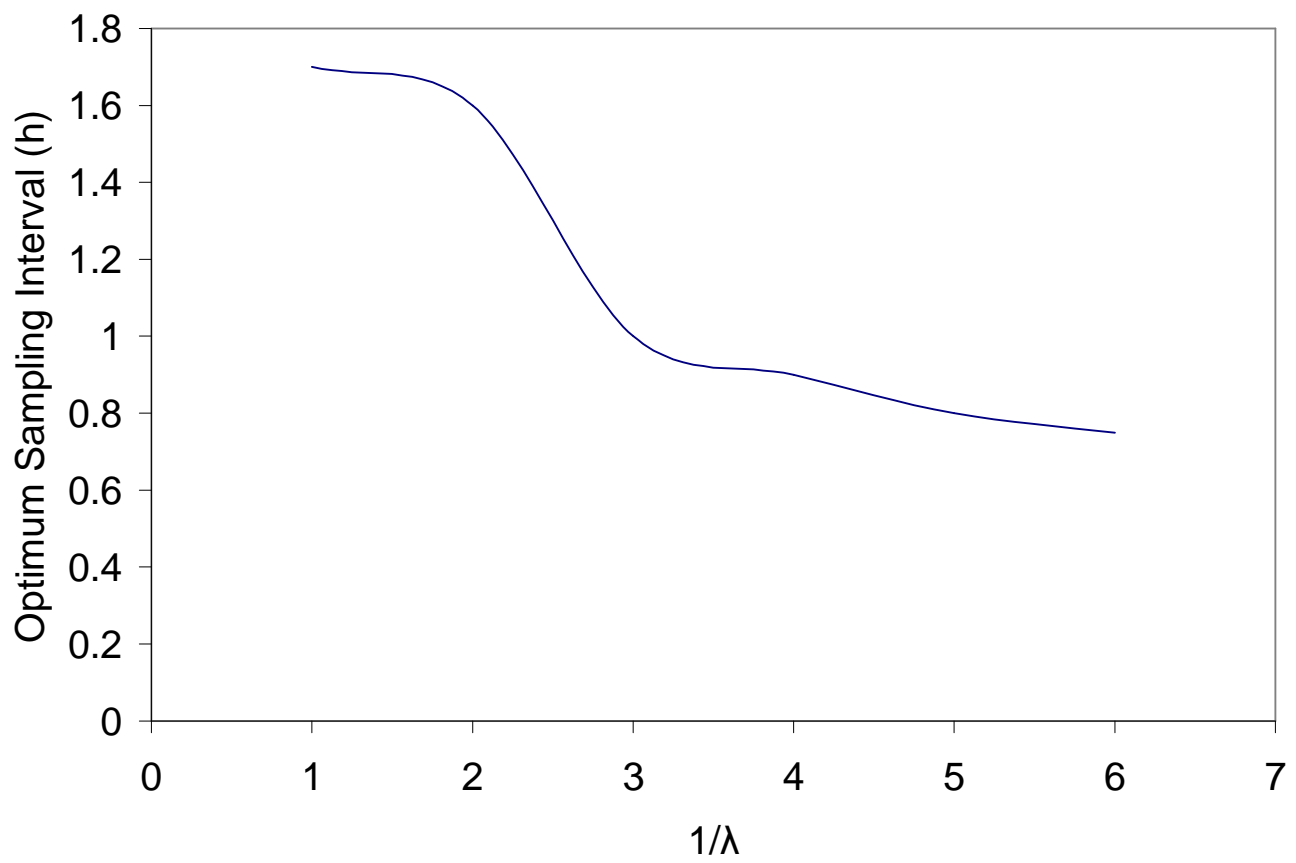

Fig. 2: Optimum sampling interval versus the mean time between assignable causes $(1 / \lambda)$. 


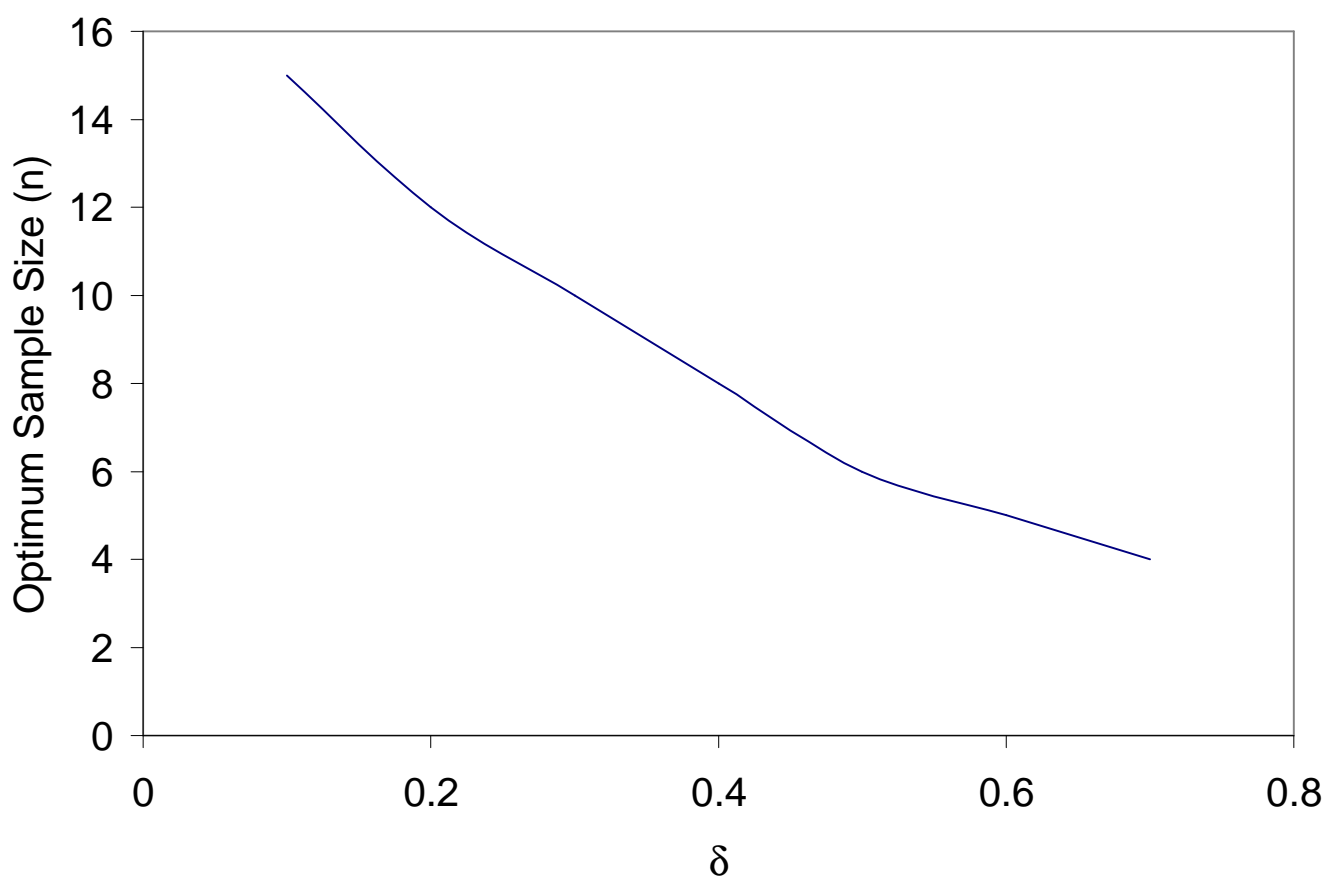

Fig. 3: Optimum sample size versus the magnitude of the shift in process average $(\delta)$.

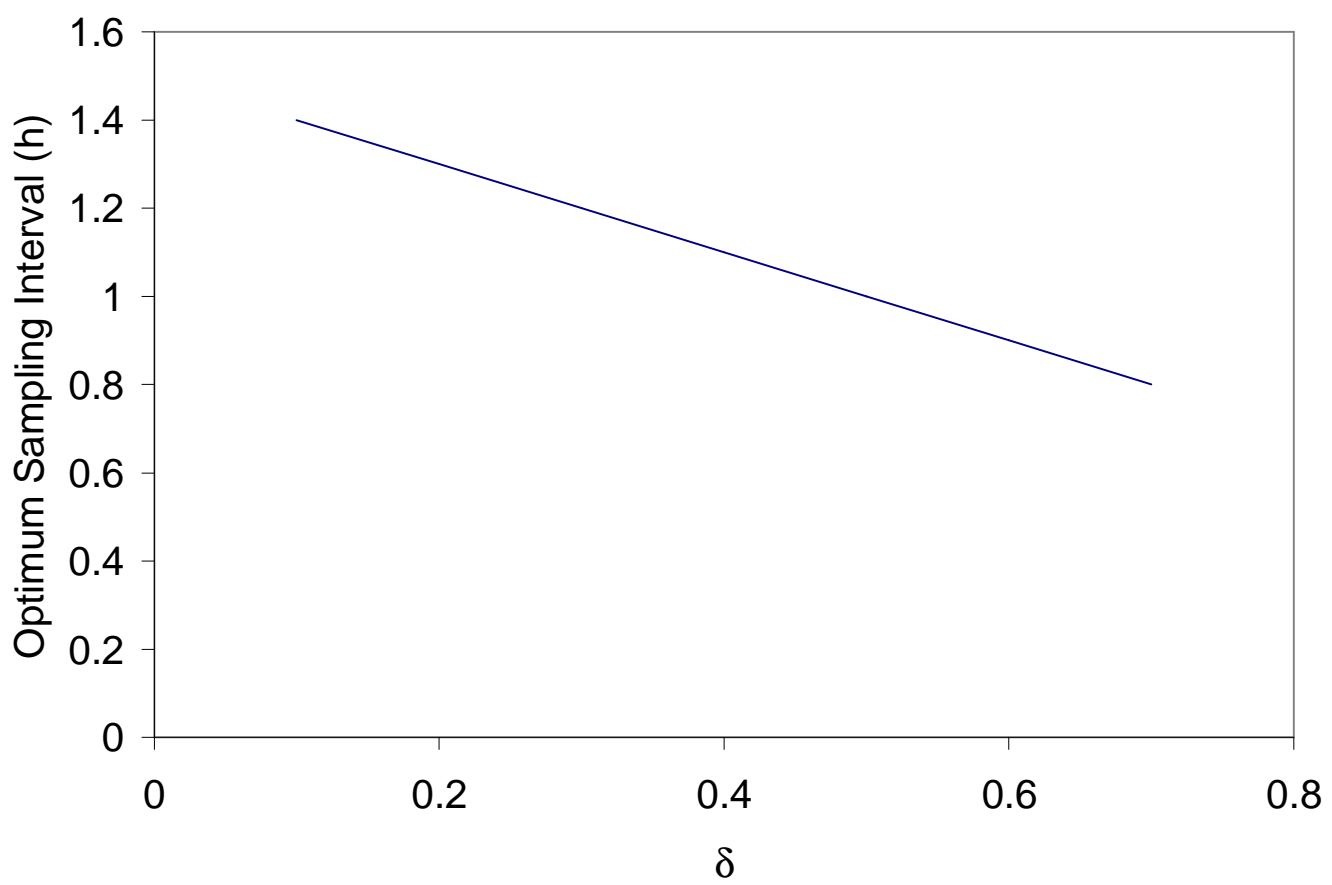

Fig. 4: Optimum sample size versus the magnitude of the shift in process average $(\delta)$. 


\section{REFERENCES}

[1] Ducan, A. J., " The Economic Design of $\overline{\boldsymbol{X}}$ - Charts used to Maintain Current Control of a Process", Journal of The American Statistical Association, Vol. 51, pp. 228-242, 1956.

[2] Ducan, A. J., " The Economic Design of $\overline{\boldsymbol{X}}$ - Charts When There is a Multiplicity of Assignable Causes", Journal of The American Statistical Association, Vol. 66, pp. 107-121, 1971.

[3] Rahim, M. A., “ Economic Model of $\overline{\boldsymbol{X}}$ - Chart Under Non - Normality and Measurement Errors ", Computers and Operation Research, Vol. 12, pp. 291299, 1985.

[4] Lorenzan, T. J. and Vance " The Economic Design of Control Charts: a Unified Approach", Technometrics, Vol. 28, pp. 3 -10, 1986.

[5] Pignatiello, J. J., " Optimal Economic Design of $\overline{\boldsymbol{X}}$ - Charts When Cost Model Parameters are not Precisely Known”, IIE Trans., Vol. 20, pp. 103 -110, 1988.

[6] Tagaras, G. J., "Economic $\overline{\boldsymbol{X}}$ - Chart with Asymmetric Control Limits", Journal of Quality Technology, Vol. 21, pp. 147-154, 1989.

[7] Saniga, E. M., “ Economic Statistical Control Chart Designs with an Application to $\overline{\boldsymbol{X}}$ and R Charts ", Technometrics, Vol. 31, pp. 313 - 320, 1989.

[8] Jaraied, M. and Zhuana, Z., " Determination of Optimal Design Parameters of $\overline{\boldsymbol{X}}$ - Charts When There is a Multiplicity of Assignable Causes", Journal of Quality Technology, Vol. 23, pp. 253-258, 1991.

[9] Yourstone, S. A. and Zimmer, w. J., " Design of Control Charts for Averages", Decision Sciences, Vol. 23, pp. 1099-1113, 1992.

[10] Williams, T. P., “ Economic, Statistical and Economic - Statistical $\bar{X}$-Chart Designs ”, Journal of Quality Technology, Vol. 26, pp. 227-238, 1994.

[11] Ho, C. and Case, k. E., " Economic Design of Control Charts: A Literature Review for 1981 - 1991 ", Journal of Quality Technology, Vol. 26, pp. 1-78, 1994.

[12] Alexander, S. M., " Economic Design of Control Charts Using the Taguchi Function", Computers and Industrial Engineering, Vol. 28, pp. 671-679, 1995.

[13] Chou, C. Y. and Cheng, P. H., " Statistically Minimum-Loss Design of Averages Control Charts ", Proc. Natl. Sci. Counc. Roc (A), Vol. 24, No.6, pp. 472-479, 2000.

[14] Chou, C. Y., Chung, C. H. and Hui, L. R. "Economic Design of $\bar{X}$ - Charts for Correlated Data ", International Journal of Production Research, Vol. 39, No.9, pp. 1931-1941, 2001.

[15] Bai, D. S., and Lee, K. T. "Variable Sampling Interval $\overline{\boldsymbol{X}}$ - Charts with an Improved Switching rule ", International Journal of Production Economics, Vol. 76, No.9, pp. 189-199, 2002.

[16] Chen, Y. K., and Liao, H. C. "Multi - Criteria Design of an $\bar{X}$ - Chart", Computer and Industrial Engineering, Vol. 46, pp. 877-891, 2004. 


\section{APPENDIX}

\section{Computer program for calculating the optimum values of the $\bar{X}$ - Control Chart Parameters}

10 REM PARAMETER SELECTIONS FOR XBAR CHARTS

20 CLS

30 INPUT "FIXD SAMPLING COST PER SUBGROUP = "; A1

40 INPUT "VARIABLE SAMPLE COST PER = "; A2

50 INPUT "COST OF FINDING AN ASSIGNABLE CAUSE = "; A3

60 INPUT "COST OF INVESTING A FALSE ALARM = "; A3P

70 INPUT "PRODUCTION RATE (PCS/HR) = ";P

80INPUT "COST (SCRAP OR REWORK) FOR A PART OUTSIDE

SPECIFICATION LIMITS = "; A

90 INPUT "VARIANCE THE PRODUCT ="; V1

100 INPUT "TOLERANCE OF THE PRODUCT (+/- ) = ";TOL

110 INPUT "MEAN TIME PROCESS REMAINS IN CONTROL (HOURS) = ";

LAMDA

120 INPUT "TIME TO TAKE A SAMPLE AND INTERRET RESULTS $($ HOURS $)=$ "; G

130 INPUT "TIME TO FIND AN ASSIGNAABLE CAUSE (HOURS = "; D

140 INPUT "SIZE OF THE SHIFT YOU WISH TO DETECT (ABOVE/BELOW

NOMINAL) $=$ "; DELTA

150 REM LISTS OF INPUTS

160 CLS: PRINT " PARAMETER SELECTION INPUTS"; PRINT: PRINT

170 PRINT "DFIXED SAMPLING COST PER SUBGROUP = "; TAB (70):A1

180 PRINT "2) VARIABLE SAMPLE COST PER SAMPLE = "; TAB (70); A2

190 PRINT "3) COST OF FINDING AN ASSIGNABLE CAUSE = "; TAB (70); A3

200 PRINT "4) COST OF INVESTIGATING A FALSE ALSE ALARM = "; TAB

(70); A3P

210 PRINT "5) PRODUCTION RATE (PCS/HR) = "; TAB (70); P

220 PRINT "6) COST (SCRAP OR REWORK) FOR APART OUTSIDE

SPECIFICATION

LIMITS = "; TAB (70); A

230 PRINT "7) VARIANCE OF THE PRODUCT = "; TAB (70); V1

240 PRINT "8) TOLERANCE OF THE PRODUCT (+/-) = "; TAB (70); TOL

250 PRINT "9) MEAN TIME PROCESS REMAINS IN CONTROL (HOURS) = ";

TAB (70); LAMDA

260 PRINT "10) TIME TO TAKE A SAMPLE AND INTERPRET RESULTS

$($ HOURS $)=$ "; TAB (70); G

270 PRINT "11) TIME TO FIND AN ASSIGNABLE CAUSE (HOURS) = "TAB

(70); D

280 PRINT "12) SIZE OF THE SHIFT YOU WISH TO DETECT (ABOVE/BELOW NOMI-

NAL) $=$ "TAB (70); DELTA

290 REM ROUTINE TO MAKE CHANGES

300 PRINT: PRINT: PRINT 
310 "INPUT IF YOU WISH TO CHANCE A VALUE ENTER THE NUMER OR ENTER 99 IF ALL THE VALUES ARE CORRECT"; E

320 IF E $=1$ GOTO 450

$330 \mathrm{IF} \mathrm{E}=2$ GOTO 470

340 IF E $=3$ GOTO 490

350 IF $\mathrm{E}=4$ GOTO 510

360 IF E $=5$ GOTO 530

370 IF E $=6$ GOTO 550

380 IF E $=7$ GOTO 570

390 IF $\mathrm{E}=8$ GOTO 590

400 IF E $=9$ GOTO 610

$410 \mathrm{IF} E=10$ GOTO 630

$420 \mathrm{IF} \mathrm{E}=11$ GOTO 650

430 IF E $=12$ GOTO 670

440 GOTO 490

450 INPUT "FIXED SAMPLING COST PER SUBGRUOP = "; A1

460 GOTO 160

470 INPUT "VARIABLE SAMPLE PER SAMPLE = "; A2

480 GOTO 160

490 INPUT "COST OF FINDING AN ASSIGNABLE CAUSE = "; A3

500 GOTO 160

510 INPUT "COST OF INVESTIGATINC A FALSE ALARM = "; A3P

520 GOTO 160

530 INPUT "PRODUCTION RATE $(\mathrm{PCS} / \mathrm{HR})=$ "; $\mathrm{P}$

540 GOTO 160

550 INPUT "COST (SCRAP OR REWORK) FOR A PART OUTSIDE

SPECIFICATION LIMITS = "; A

560 GOTO 160

570 INPUT "VARIANCE OF THE PRODUCT = "; V1

580 GOTO 160

590 INPUT "TOLERANCE OF THE PRODUCT (+/-) = "; TOL

600 GOTO 160

610 INPUT "MEAN TIME PROCESS REMAINS IN CONTROL = "; LAMDA

620 GOTO 160

630 INPUT "TIME TO TA;E A SAMPLE AND INTERPRET RESULTS = ";G

640 GOTO 160

650 INPUT "TIME TO FIND AN ASSIGNABLE CAUSE (HOURS) = "; D

660 GOTO 160

670 INPUT "SIZE OF THE SHIFT YOU WISH TO DETECT (ABOVE/BELOW

NOMINAL) $=$ "; DELTA

680 GOTO 160

690 LPRINT: LPRINT: LPRINT

700 LPRINT: LPRINT: LPRINT TAB (15): "VARIABLES AND PARAMETER

SELECTION FOR XBAR CHART"

710 LPRINT: LPRINT

720 LPRINT TAB (14); "1) FIXED SAMPLING COST PER SUBGROUP = ";

LPRINT TAB (67) 
USING" \# \#. \# \# "; A1

730 LPRINT TAB (14) VARABLE SAMPLE COST PER SAMPLE"; LPRINT

TAB (67) USING" \# \# \#. \# \# "; A2

740 LPRINT TAB (14); "3) COST OF FINDING AN ASSIGNABLE CAUSE";

LPRINT

TAB (67) USING" \# \# \#. \# \# "; A3

750 LPRINT TAB (14); "4) COST OF INVESTIGATING A FALSE ALARM";:

LPRINT TAB(67)USING "***. \# \# "; A3P

760 LPRINT TAB (14); "5) PRODUCTION RATE (PCS/HR) ";: LPRINT

TAB (67) USING" \# \# \# \# \# \# "; P

770 LPRINT TAB (14): "6) COST (SCRAP/REWORK) FOR A PART OUTSIDE

SPEC LIMITS = "; LPRINT

TAB (67) USING "\# \# \#. \# \# "; A

780 LPRINT TAB (14); "7) VARIANCE OF THE PRODUCT"; LPRINT

TAB (64) USING "\#. \# \# \# \# \# \# \# "; V1

790 LPRINT TAB (14); "8) TOLERANCE OF THE PRODUCT (+ / -)"; LPRINT

TAB (67) USING

"\# . \# \# \# \# "; TO;

800 LPRINT TAB (14); "9) MEAN TIME PROCESS REMAINS IN CONTROL (HOURS) "; LPRINT

TAB (67) USING "\# \# \# \# \# . \# "; LAMDA

810 LPRINT TAB (14); "10) TIME TO TAKE A SMPLE AND INTERPRET

RESULTS (HRS) "; LPRINT

TAB (68) USING "\#. \# \# \# "; G

820 LPRINT TAB (14) TIME TO FIND AN ASSIGNABLE CAUSE (HOURS )

";:LPRINT

TAB (69) USING "\# \#. \# ";D

830 LPRINT TAB(14); "12)SIZE OF THE SHIFT YOU WISH TO DETECT ( + / - )

";:LPRINT TAB(67)USING "\# . \# \# \# \# "; DELTA

840 LPRINT: LPRINT

850 LPRINT TABS (19): "N -UP SIZE"

860 LPRINT TABS (19): "K -OEFFICIENT TO DETERMINE CONTROL LIMITS"

870 LPRINT TAB (19); "H-SAMPLING INTERVAL (HOURS)"

880 LPRINT"LPRINT

890 LPRINT TAB(13); "N"; TAB(24); "K"; TAB(32);"H" TAB(42);"ALPHA";

TAB(54);"POWER";

TAB (67);"COST"

900 LPRINT TAB (13);"-_";TAB(23);:-._";TAB(31);"- —-"TAB(67);"- -"

910 FOR $\mathrm{N}=2$ TO 12

$920 \mathrm{E} \quad \mathrm{CMIN}=9999999$ !

930 FOR $\mathrm{H}=.1$ to 2 step .1

940 for $\mathrm{k}=1$ ! To 4 ! STEP .1

950 REM DETERMINE ALPHA

$960 \mathrm{X}=-\mathrm{K}$

$970 \mathrm{Y}=2 *(\mathrm{~K})$

$980 \mathrm{C}=\mathrm{Y} / 8$ 
$990 \mathrm{~S}=\mathrm{C} /(3 * \mathrm{SQR}(2 * 3.14159)) *\left(\mathrm{EXP}\left(-.5 \mathrm{X}^{\wedge} 2\right)+4 * \operatorname{EXP}\left(-.5^{*}\left(\mathrm{X}+\mathrm{Y} / 8^{\wedge}\right) 2+2^{*} \mathrm{EXP}(-\right.\right.$ $\left..5^{*}(\mathrm{X}+\mathrm{Y} / 4)^{\wedge} 2\right)+4^{*} \mathrm{EXP}\left(-.5^{*}\left(\mathrm{X}+3^{*} \mathrm{Y} / 8\right)^{\wedge} 2\right)+2^{*} \mathrm{EXP}\left(-.5(\mathrm{X}+\mathrm{Y} / 2)^{\wedge} 2\right)+4^{*} \mathrm{EXP}(-$ $.5^{*}\left(\mathrm{X}+5^{*} \mathrm{Y} / 8^{\wedge} 2\right)+2^{*} \mathrm{EXP}\left(-.5\left(\mathrm{X}+6^{*} \mathrm{Y} / 8\right)^{\wedge} 2\right)+4^{*} \mathrm{EXP}\left(-.5^{*}\left(\mathrm{X}+7^{*} \mathrm{Y} / 8\right)^{\wedge} 2\right)+\mathrm{EXP}(-$ $\left.\left..5^{*}(\mathrm{X}+\mathrm{Y})^{\wedge} 2\right)\right)$

1000 ALPHA $=1-\mathrm{S}$

1010 IFALPHA $<0$ THEN ALPHA $=0$

$1020 \mathrm{~L} 1=\mathrm{A} / \mathrm{TOL} \wedge 2 * \mathrm{~V} 1$

$\left.1030 \mathrm{~V} 2=\mathrm{V} 1+\mathrm{DELTA}^{\wedge} 2\right)$

$1040 \mathrm{~L} 2=\mathrm{A} / \mathrm{TOL}^{\wedge} 2 * \mathrm{~V} 2$

1050 REM DETERMINE (1- BETA)

1060 NDELTA = DELTA/SQR (V1)

$1070 \mathrm{~T} 1=$ NDELTA $*$ SQR $(\mathrm{N})-\mathrm{K}$

$1080 \mathrm{~T} 2=-\mathrm{NDELTA} *$ SQR $(\mathrm{N})-\mathrm{K}$

$1090 \mathrm{X}=-3.5$

$1100 \mathrm{Y} 1=\mathrm{T} 1-\mathrm{X}$

$1110 \mathrm{C}=\mathrm{Y} 1 / 8$

$11120 \mathrm{~S} 1=\mathrm{C} /(3 * \mathrm{SQR}(2 * 3.14159)) *\left(\operatorname{EXP}\left(-.5 \mathrm{X}^{\wedge} 2\right)+4 * \operatorname{EXP}\left(-.5 *(\mathrm{X}+\mathrm{Y} 1 / 8)^{\wedge} 2\right)+\right.$

$2 * \operatorname{EXP}\left(-.5^{*}(\mathrm{X}+\mathrm{Y} 1 / 4)^{\wedge} 2\right)+4 * \operatorname{EXP}\left(-.5^{*}\left(\mathrm{X}+3^{*} \mathrm{Y} 1 / 8\right)^{\wedge} 2\right)+2 * \operatorname{EXP}\left(-.5^{*}(\mathrm{X}+\mathrm{Y} 1 / 2)^{\wedge} 2\right)$

$+4 * \operatorname{EXP}\left(-.5^{*}\left(\mathrm{X} 5^{*} \mathrm{Y} 18\right)^{\wedge} 2\right)+2^{*} \mathrm{EXP}\left(-.5^{*}\left(\mathrm{X}+6^{*} \mathrm{Y} 1 / 8\right)^{\wedge}+4 * \mathrm{EXP}-.5^{*}(\mathrm{X}\right.$

$\left.\left.+7 * \mathrm{Y} 1 / 8)^{\wedge} 2\right)+\operatorname{EXP}\left(-.5^{*}(\mathrm{X}+\mathrm{Y} 1)^{\wedge} 2\right)\right)$

$1130 \mathrm{X}=-5$

$1140 \mathrm{Y} 2=\mathrm{T} 2-\mathrm{X}$

$1150 \mathrm{C} 2 \mathrm{Y} 2 / 8$

$1160 \mathrm{~S} 2=\mathrm{C} 2 /(3 * \mathrm{SQR}(2 * 3.14159)) *\left(\operatorname{EXP}\left(-.5 \mathrm{X}^{\wedge} 2\right)+4 * \operatorname{EXP}\left(-.5 *(\mathrm{X}+\mathrm{Y} 2 / 8)^{\wedge} 2\right)+\right.$

$2^{*} \operatorname{EXP}\left(-.5^{*}(\mathrm{X}+\mathrm{Y} 2 / 4)^{\wedge} 2\right)+4^{*} \operatorname{EXP}\left(-.5^{*}\left(\mathrm{X}+3^{*} \mathrm{Y} 2 / 8\right)^{\wedge} 2\right)+2^{*} \mathrm{EXP}\left(-.5^{*}(\mathrm{X}+\mathrm{Y} 2 / 2)^{\wedge} 2\right)$

$+4 * \operatorname{EXP}\left(-.5^{*}\left(\mathrm{X} 5^{*} \mathrm{Y} 2 / 8\right)^{\wedge} 2\right)+2 * \operatorname{EXP}\left(-.5^{*}\left(\mathrm{X}+6^{*} \mathrm{Y} 2 / 8\right)^{\wedge}+4^{*} \mathrm{EXP}-.5^{*}(\mathrm{X}\right.$

$\left.\left.+7 * \mathrm{Y} 2 / 8)^{\wedge} 2\right)+\operatorname{EXP}\left(-.5^{*}(\mathrm{X}+\mathrm{Y} 2)^{\wedge} 2\right)\right)$

1170 REM BETA IS 1 - BETA

$1180 \mathrm{BETA}=\mathrm{S} 1+\mathrm{S} 2$

$1190 \mathrm{EC}=(\mathrm{A} 1+\mathrm{A} 2 * \mathrm{~N}) / \mathrm{H}+\left(\mathrm{A} 3+\mathrm{A} 3 \mathrm{P}^{*} \mathrm{ALPHA} * \mathrm{LAMDA} / \mathrm{H}+\right.$

$\mathrm{A} * \mathrm{VI} * \mathrm{P} / \mathrm{TOL}{ }^{\wedge} 2 * \mathrm{LAMDA}+\mathrm{A} * \mathrm{~V} 2 * \mathrm{P} / \mathrm{TOL}{ }^{\wedge} 2 * \mathrm{H} / \mathrm{BETA}-(\mathrm{H} *(.5-1 / \mathrm{LAMDA} * \mathrm{H} / 12))$

$\left.\left.+\mathrm{G}^{*} \mathrm{~N}+\mathrm{D}\right)\right) /\left(\right.$ LAMDA + H/BETA $-\mathrm{H}^{*}(.5-\mathrm{H} / 12 /$ LAMDA $\left.)+\mathrm{G}^{*} \mathrm{~N}+\mathrm{D}\right)$

$1200 \mathrm{IF}$ EC > ECMIN THEN GOTO 1260

$1210 \mathrm{HBEST}=\mathrm{H}$

$1230 \mathrm{KBEST}=\mathrm{K}$

1240 ALPHAB $=$ ALPHA

1250 BETABEST $=$ BETA

1260 NEXT K

1270 NEXT H

1280 LPRINT TAB (14) USING" \# \# "; N; LPRINT TAB (23) USING " \#. \# ";

KBEST; LPRINT TAB (31) USING " \#. \# "; HBEST; LPRINT TAB (41) USING " \#. \# \# \# \# "; ALPRINT TAB (54) USING " \# . \# \# \# \# "; BETABEST; LPRINT TAB (65) USING " \# \# \# \#. \# \# "; ECMIN

1290 NEXT N

1300 LPRINT CHR\$ (12)

1310 INPUT "make a change and run again (Y/N)?"; N\$

1320 IF N\$ = "Y" GOTO 160 


\title{
تأثير التغيريه في متوسط عملية الإنتاج على القيم الاقتصادية لمتغيرات خرائط الضبط للمتوسطات
}

\author{
عبدالحميد وزير عبدالحميا \\ قسم هندسة الإنتاج و التصميم \\ كلية التعليم الصناعي - جامعة بنسويف الأناجيم
}

عند استخدام خر ائط ضبط الجودة للمتوسطات لمر اقبة التغير في منوسطات صفة الجودة

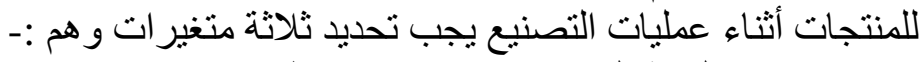

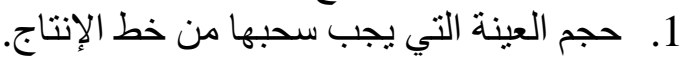
2.

3. حد الضبط العلوي وحد الضبط السفلى لخريطة ضبط الجودة.

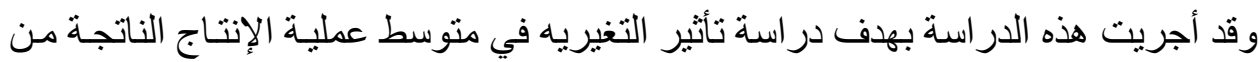

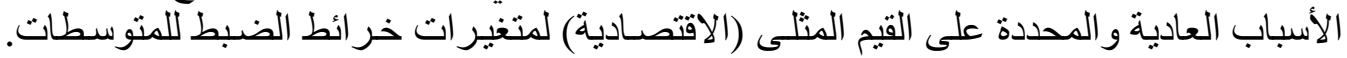

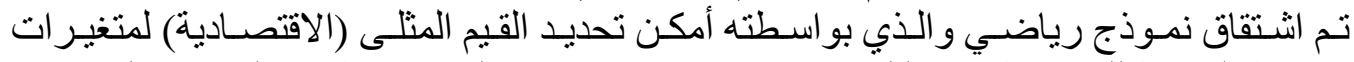

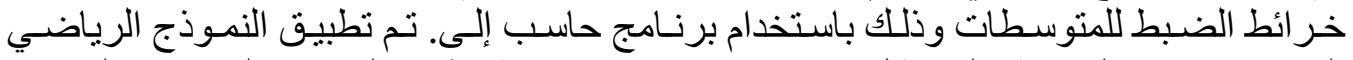

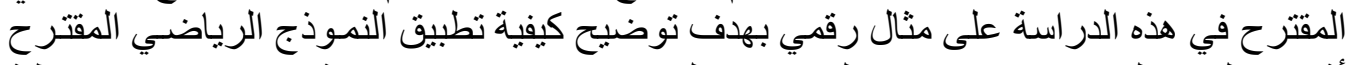

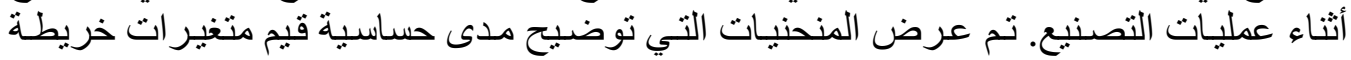

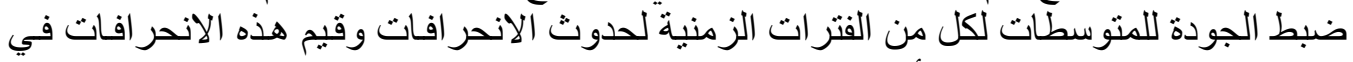
متوسط صفة الجودة للمنتجات أثناء عمليات التصنيع. وقد خلص البند البحث إلى النتائج التالية:1. يجب زيادة حجم العينة المسحوبة من خط الإنتاج عند زيادة تكرار حدوث الانحر افات في منوسط صفة الجودة للمنتجات.

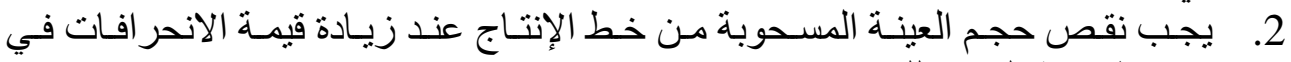
متوسط صفة الجودة للمنتجات. 